\title{
Processes Underlying MNE Subsidiary Absorptive Capacity: Evidence from Emerging Markets
}

\author{
Jing Zeng ${ }^{1}$ (D) $\cdot$ Keith W. Glaister ${ }^{2} \cdot$ Tamer Darwish $^{3}$
}

Received: 14 November 2018 / Revised: 29 May 2019 / Accepted: 17 June 2019 / Published online: 22 July 2019 (c) The Author(s) 2019

\begin{abstract}
We explore the determinants of absorptive capacity by examining how managers of MNE subsidiaries operating in emerging markets recognize, assimilate and apply external knowledge. From analysis of the subsidiaries of 12 MNEs with data from a total of 62 informants from China, India, Brazil and Kenya, six constructs emerged: prior knowledge significance, unlearning, explorative scanning, transformative learning, exploitative application and organization context. Through the iteration of data and theory, we develop a model, which presents a process framework that suggests the dynamic relationships among the emergent concepts underlying absorptive capacity. By identifying and explicating key actions and practices that have previously been largely treated as implicit in the absorptive capacity literature, the study enriches understanding of the micro-processes of absorptive capacity.
\end{abstract}

Keywords Absorptive capacity · Emerging economies $\cdot$ Innovation $\cdot$ Learning

\section{Introduction}

What drives the ability of MNE subsidiaries to absorb knowledge in emerging markets? To answer this question, most prior literature has focused on the internal corporate embeddedness of MNE subsidiaries (Bouquet and Birkinshaw 2008), accentuating knowledge transfer among subsidiaries and MNE headquarters and peer subsidiary units throughout the world. This focus means that the existing literature offers limited insight into the larger questions of how MNE subsidiaries develop their ability to absorb external knowledge in the local institutional setting in ways that generate competitive advantage. The exceptions are the relatively few studies

Jing Zeng

j.zeng@kent.ac.uk

1 University of Kent, Kent Business School, Canterbury, UK

2 University of Leeds, Leeds University Business School, Leeds, UK

3 University of Gloucestershire, The Park, Cheltenham, UK 
that have sought to understand subsidiary absorptive capacity by examining how they engage in their own learning and knowledge acquisition processes conditioned by the local environment (e.g., Andersson et al. 2014; Fan et al. 2015; Fang and Zou 2010). The research gap warrants attention given the increasingly significant role played by subsidiaries in MNE innovation (Birkinshaw 1998; Venaik et al. 2005) and the unique and valuable ways in which knowledge is combined and applied to create competitive advantage (Cohen and Levinthal 1990).

Prior research has implicitly assumed the universal beneficial effects of experiential learning and the augmentation of firm-specific advantages by capitalizing on host countries' unique resource endowments and location-specific advantages (e.g., Birkinshaw 1998; Lu and Beamish 2001). However, such research has not uncovered distinct locational effects and how these effects may impact on managerial attitudes to learning at subsidiary level. This understanding is important, as a growing number of IB scholars have argued that MNEs when operating in one type of institutional environment, may draw erroneous inferences and apply incorrectly their knowledge and experience in a different institutional environment, which may actually harm their subsidiaries (e.g., Kim et al. 2015; Volberda and Lewin 2003; Zeng et al. 2013). Many MNEs are attracted by the opportunities and potential economic growth offered from emerging markets such as China, India, Mexico and Brazil (de Soto 2000; Hart and Christensen 2002). However, these markets present extreme cultural, geographical, religious, ethnic and linguistic heterogeneity (Hammond et al. 2007; Webb et al. 2010), which signifies fundamentally new challenges for the field of international strategy for MNEs. Hence, although we know that absorptive capacity represents a key organizational capability, existing knowledge on why variations exist across MNE subsidiaries in emerging markets to engage in localized learning remains not sufficiently understood (Cano-Kollmann et al. 2016; Fan et al. 2015). Therefore, an understanding of the process of how subsidiary managers engage in local learning and how this learning process interacts with the MNE's path dependent knowledge should capture important unobserved and under-researched effects of subsidiary local learning capabilities. Recently scholars have called for greater understanding of the knowledge connectivity between MNEs and location (e.g., Cano-Kollmann et al. 2016) and suggested the need to account for the active role that subsidiaries play in interaction with the local institutional environment (e.g., Cantwell 2014; Teece 2014). This understanding is theoretically significant in order to provide new insights into the process of the subsidiary's learning capabilities. It is also of great relevance to emerging economies where the institutional environment is radically different from that of developed economies. Although MNEs contribute substantially to host country technological and economic development (Hart and Christensen 2002), they are plagued by high failure rates (Rondinelli and London 2003). Consequently, a greater understanding of how subsidiaries develop and apply absorptive capacity to engage in localized learning is essential (Cantwell 2014). Accordingly, the aim of this paper is to expand and build upon understanding of absorptive capacity by exploring the following central research question: How do individual managers of MNE subsidiaries operating in different and conflicting institutional emerging markets, such as, China, India and Brazil recognize, assimilate and apply external knowledge? 
In building our contextualized perspective, we define different and conflicting institutional environments as the host countries that have cultural, geographical, religious, ethnic and linguistic heterogeneity, and have less developed/poor market supporting mechanisms, such as infrastructure, than the MNE home country. In doing so we explore a process-oriented view of absorptive capacity rather than adopting an outcome-driven perspective. Contrary to models dealing with "covariation among dependent and independent variables" (Langley et al. 2013, p. 2) that dominate understanding of absorptive capacity in the IB context, process models attempt to capture the sequence of certain conditions and events in explaining how learning unfolds over time (Langley 1999). Such an approach can provide a holistic understanding of a phenomenon as it captures both external (e.g., environment) and internal (e.g., organizational inertia) aspects in theorizing (Tripsas 2009). Some scholars (e.g., Felin and Hesterly 2007; Nag and Gioia 2012) have also critiqued the predominant approach to the study of knowledge-based capabilities in organizations as overly collective in its treatment and call for empirical investigation of the individual drivers and process of knowledge-based value: Thus opening up the proverbial black box of the firm by explicating the underlying a priori capabilities and knowledge of the individuals involved provides a natural starting point and micro-foundation for explaining the creation of new value (Felin and Hesterly 2007). Studying absorptive capacity as a temporal process, offers a perspective that is underrepresented in management research but essential to understanding the transformative process by which knowledge become goals, actions, and systemic outcomes.

This study adds to the body of research examining absorptive capacity at the subsidiary level and makes a contribution to the existing literature in two important ways. First, although the IB literature recognizes the importance of the subsidiary in driving the firm's competitive advantage, investigation of the specific processes by which subsidiary managers operating in a radically different host country environment recognize, assimilate and use knowledge at the local level has been limited. We introduce an inductive process model that not only shows that subsidiary managers differ in their beliefs about path dependent knowledge, but also shows how those differences lead to ways in which knowledge was searched, assimilated and used at local level. Second, our analysis indicates different patterns associated with managers' ability to absorb local knowledge. Our data shows that managers differ in their scanning intensity, frequency and scale to absorb new knowledge. Such scanning difference leads to a degree of dialectic interaction with the local informal partners such as customers and local communities. Such dialectic interaction often leads to innovative ways of executing absorbed knowledge. This pattern of actions can be used as a crucial precursor for the ability of the subsidiary to absorb, assimilate and execute local knowledge.

The paper is structured as follows. In the next section, we review the absorptive capacity literature in the international business field. We then set out the research design and method of the study. This is followed by a discussion of the findings. We distil the theoretical insights that emerge from the study and provide a set of propositions related to a theoretical model of the processes underlying MNE subsidiary absorptive capacity. We then provide theoretical and practical implications of the findings, identify the limitations of the study and avenues for future research. 


\section{Theoretical Background}

International business (IB) scholars have long acknowledged the centrality of the firm's knowledge assets to an understanding of the raison d'être of multinational enterprises (MNEs) (Buckley and Casson 1976; Cantwell 1989; Caves 1971; Hymer 1960). The MNE's ability to leverage the knowledge dispersed across its various foreign markets, capitalizing on and maximizing learning from these local markets, is a fundamental strategic imperative (Bartlett and Ghoshal 1989). Several IB scholars have investigated the questions of generation, assimilation, and transfer of knowledge created in various parts of the MNE (Fan et al 2015; Fang and Zou 2010; Gupta and Govindarajan 2000). Central to this is an emphasis on absorptive capacity.

Absorptive capacity encompasses human capital and structural features of the organization, such as strategic and organizational flexibility, which is crucial in emerging economies due to the highly volatile institutional environment (Cohen and Levinthal 1990; Lane and Lubatkin 1998; Lane et al. 2001; Uhlenbruck et al. 2003). Central to a firm's absorptive capacity is the assumption that prior, related individual units of knowledge are available within the firm that enhance the acquisition and use of new knowledge (Cohen and Levinthal 1990; Kim 2001). This notion is based on the premise that firms can effectively untangle causalities based on prior activities and draw accurate inferences (Levinthal and March 1993; Levitt and March 1988). This is particularly pertinent in the case of the MNE, for which coordinating, distributing, and using valuable knowledge within its global network of subsidiaries is central to distinctive competency (Roth and Morrison 1992).

Cohen and Levinthal's (1990) original definition of absorptive capacity was added to by Zahra and George (2002) to arrive at the following dimensions: acquisition, assimilation, transformation, and exploitation of knowledge. The first two dimensions constitute potential absorptive capacity, the latter two dimensions comprise realized absorptive capacity. Lane et al. (2006) further distinguished exploratory, transformative, and exploitative learning processes. Following these conceptualizations, absorptive capacity in the knowledge management capacity framework focuses on knowledge acquisition, i.e. potential absorptive capacity (Zahra and George 2002) and exploratory learning (Lane et al. 2006). Todorova and Durisin (2007) further proposed new model components that come after acquisition: Assimilation and transformation, with both processes being conducted in parallel to each other.

\subsection{Internal Factors-Knowledge and Stock Flows in MNEs}

The process by which MNEs create value from knowledge was initially conceptualized as a linear sequence: Knowledge was created in the firm's home base and then diffused worldwide in the form of new products and processes (Almeida et al. 2002). In this view of the process, knowledge transfer tended to be internalized within the MNE in order to avoid the transaction costs associated with market contracts in relation to knowledge assets. Many scholars have provided important insights on absorptive capacity in the context of MNEs. For instance, prior studies have utilized R\&D spending, structural characteristics, and patent-based proxies for measuring 
absorptive capacity in firms (e.g., Cohen and Levinthal 1990; Gupta and Govindarajan 2000; Zhang et al. 2010); knowledge transfers within MNE networks and strategic alliances (Fang and Zou 2010; Lane and Lubatkin 1998; Schleimer and Pedersen 2013; Song 2014); knowledge source characteristics, knowledge recipient characteristics, and how their relationship affects the transfer of knowledge in the MNE (Caligiuri 2014; Gupta and Govindarajan 2000; Yang et al. 2008). These studies have mainly focused on knowledge- and experience-based explanations. MNEs are generally perceived as repositories of routines endowing them with a capacity to search (Nelson and Winter 1982) that are often unique and difficult to imitate. According to this view, the path-dependent proximity to tacit knowledge and prior and commensurate skills drives international exploitation of knowledge and expansion in the form of new products and processes (Almeida et al. 2002; Nelson and Winter 1982).

This perspective was criticized for being a naive evolutionary journey (Volberda and Lewin 2003) that offers an insufficient explanation for the development of the firm's new knowledge. Many scholars argue that the MNE's prior knowledge base and its frames of experience interpretation are largely imprinted by the home country's institutional environment (Bhagat et al. 2002; Björkman et al. 2007), therefore, MNEs stick with what they have and have to live with what they lack (Zeng et al. 2013). Consequently, when MNEs are exposed to a new, radically different and complex institutional environment, they are more vulnerable as they lack the absorptive capacity required to value and assimilate the external information in the host country setting (Johanson and Vahlne 1977). This knowledge gap erodes an MNE's ability to learn from its experience, by reducing its ability to interpret and assimilate its local experience (Barkema and Drogendijk 2007). For example, Zeng et al. (2013) argued that MNEs may draw erroneous inferences and learn incorrectly from their early international expansion when new to a dissimilar culture, because their learning abilities are eroded by cultural differences. This view is echoed by many scholars who point out that firms may be susceptible to learning errors that lead to violations of their core assumptions (e.g., Levinthal and March 1993; Levitt and March 1988).

Although the concept of absorptive capacity recognizes that assimilating new knowledge requires prior knowledge (Cohen and Levinthal 1990), learning cannot be decoupled from environmental conditions such as the competitive structure and institutional infrastructure (Levitt and March 1988). Unlearning, therefore, plays a crucial role when newly acquired knowledge is incompatible with prior organizational knowledge (Cepeda-Carrion et al. 2012; Lavie 2006). Unlearning has been defined by Harvey and Buckley (2002, p. 375) as "a systematic removal of information that is outdated or no longer useful to management decision-making". In other words, the extent to which a subsidiary needs to unlearn in order to learn new knowledge may vary from resource rich to resource poor countries in terms of strategic factor markets (Zahra et al. 2011). Cepeda-Carrion et al. (2012) propose that unlearning is not only a mechanism to forget or discard old knowledge but is also the way in which companies are able to develop and make room for new knowledge. This is particularly salient in the context of MNEs, where their subsidiaries operate in different, often complex and conflicting institutional environments (Kostova et al. 
2008), and where the knowledge accumulated and developed from the home country may not easily transfer to, or be applicable in, the host country.

\subsection{External Embeddedness-The Role of the MNE Subsidiary}

The role of MNE subsidiaries has received a great deal of attention in the IB literature (Bartlett and Ghoshal 1989; Birkinshaw 1998; Birkinshaw and Morrison 1995; Bouquet and Birkinshaw 2008). Following conceptualization of the MNE as an interorganizational network encompassing both internal and external linkages (Barlett and Ghoshal 1990), most of the IB literature adopts a top-down approach to understanding how the MNE is able to exert power and influence across its interorganizational network focusing on corporate embeddedness (Bouquet and Birkinshaw 2008). However, this perspective overlooks the important active role of managerial agency on the part of the subsidiary unit in changing the power balance in the system. Rather than acting as receptive units (Jarillo and Martinez 1990) with a basic mandate (Delany 1998), subsidiaries are able to create strong connections with corporate and local external stakeholders such as suppliers, customers and governments.

While there has been significant work on the subsidiary's absorptive capacity in relation to its corporate embeddedness (e.g., Caligiuri 2014; Gupta and Govindarajan 2000; Lane and Lubatkin 1998; Schleimer and Pedersen 2013; Song 2014), the ability of the subsidiary to recognize, assimilate and exploit local external knowledge in order to undertake innovation is incompletely understood. According to Cohen and Levinthal (1990), a firm's prior related knowledge confers its absorptive capacity, defined as its ability "to recognize the value of new information, assimilate it, and apply it to commercial ends" (Cohen and Levinthal 1990, p. 128). Therefore, when an MNE's subsidiary operates in a dissimilar institutional environment, the MNE may draw erroneous inferences and learn incorrectly from its knowledge and experience, which may actually harm subsequent subsidiaries (e.g., Kim et al. 2015; Volberda and Lewin 2003; Zeng et al. 2013).

Indeed, an individual's attention to cues and the interpretation of these cues are influenced by culture, training, and background (Feldman 1986). Therefore, when employees enter a radically different and complex host country environment, the experience and knowledge accumulated in a different institutional context may prevent them from detecting true causal relations in the host environment (Feldman 1986; Prashantham and Floyd 2012). There is a scant literature, however, on how subsidiary managers' attitudes toward learning in an emerging host country can be actively developed and expanded by the knowledge source. Absorptive capacity scholars refer to so-called 'activation triggers' (Fosfuri and Tribó 2008) or 'crises' (Todorova and Durisin 2007; Zahra and George 2002), which are often linked with innovation and competitive advantage, but prior studies generally do not specify those actions and mechanisms that can be enforced in order to promote absorptive capacity at the MNE subsidiary level (Todorova and Durisin 2007). Not knowing what influences absorptive capacity at subsidiary level can be especially detrimental for the MNE, considering that its competitive advantage stems from superior global leveraging of knowledge (Doz et al. 2001). 
In summary, most of the IB literature has focused on knowledge- and experiencebased explanations that highlight path dependency, while the role of the attitude of management to learning at the subsidiary level is clearly underdeveloped. This limited attention is surprising, especially since Cohen and Levinthal (1990) highlighted that what creates competitive advantage from knowledge is the unique and valuable ways in which it is combined and applied. Indeed, while the path dependencies are accounted for, significant unexplained variance in terms of subsidiary absorptive capacity remains. This unexplained variance may capture important unobserved and under-researched attitudes of management to learning and adaption of business processes in MNE subsidiaries operating in emerging economies. An understanding of the process aspect of absorptive capacity should shed new light on how a manager develops and uses absorptive capacity in the MNE's subsidiary. To understand more fully the role of external knowledge in the creation of distinctive competencies, there is a need to explore the mechanisms that could lead to variations in managers' absorptive capacity. Several scholars (e.g., Cano-Kollmann et al. 2016; Cantwell 2014; Teece 2014) also suggest the need to account for a capability-based theory of the MNE in appreciating the active role that subsidiaries play in interaction with the local institutional environment. We address this gap in the literature by adopting absorptive capacity as a guiding theoretical logic to obtain a fine-grained understanding of the processes by which individual managers of MNE subsidiaries operating in emerging markets, such as, China, India and Brazil value, assimilate and exploit local knowledge.

\section{Research Design}

Given the relatively new and unexplored nature of the phenomenon, we conducted an inductive, multiple case study (Eisenhardt 1989; Yin 1984). Inductive studies are particularly helpful in developing theoretical insights which existing theory does not address well and when the research question is process oriented, such as ours. Multiple cases can create opportunities to triangulate information collected and to augment external validity, help guard against observer bias and allow for replication logic (Eisenhardt 1989; Miles and Huberman 1994; Yin 1984). As process research, this study focuses on understanding the causal dynamics of a particular setting (Mohr 1982) and offers a more fine-grained lens to understand the processes of absorptive capacity in the external embeddedness role of subsidiaries. We used the method described by Gioia et al. (2013) to collect and analyse our data, focusing on the contextual interrelationships regarding absorptive capacity at managerial level to address existing theory.

\subsection{Empirical Setting}

Our case studies are derived from MNEs from a diverse range of industries that operate in emerging economies, including China, India, Brazil and Kenya. Table 1 provides background information on the 12 case studies. We adopted a purposeful 
sampling approach in selecting the MNEs for the study. First, we adopted a sampling form that seeks 'maximum variation' (Lincoln and Guba 1985; Patton 2002) where the sample cases are from diverse industries operating in different emerging economies, but also include contrasting cases (Lincoln and Guba 1985). Our sampling selection is also restricted by the accessibility of MNEs' subsidiaries operating in emerging markets. In total, 12 MNE subsidiaries were chosen for this study, operating in the following sectors: consumer goods (2 MNEs), telecommunications (2), agriculture (1), financial services (2), automobiles (2), online retailing (1), and health care (2). The diversity of industries was planned because of the exploratory nature of the study. We purposefully chose subsidiaries that are embedded well into the local external network and were highly active in pursuing opportunities and knowledge in local markets, and also ones that were not. We defined the extent of such external embeddness as derived by our informants, in terms of positive characteristics (e.g., "We were amazed by the ideas and opportunities here") and negative ones (e.g., "this is a complete mess"). Such polar sampling is a particularly effective theoretical sampling approach because it makes the emergent constructs and theoretical relationships "transparently observable" (Pettigrew 1990, p. 275).

\subsection{Data Collection}

We developed a close working relationship with the China Foreign Trade Centre which allowed access to MNEs in China and also facilitated access to MNEs in other countries. Various contacts were made including personal visits, phone calls and emails, with a description of the intended study depicted to potential participants as aimed at understanding the learning processes of absorptive capacity of MNE subsidiaries in emerging economies. Over a 25-month period, 62 interviews were conducted tracking the process over 5 years of how subsidiaries recognize, assimilate and apply external knowledge in the host countries. Cross-hierarchical participants were selected, including managers who play key roles at the subsidiary level and lower-echelon employees. Such data collection helped us to validate the data we gathered from a managerial perspective. A total of 41 face-to-face interviews were conducted. Due to the geographical distance, a further 21 interviews were conducted either through telephone or Skype.

We followed a semi-structured interview protocol that began with general questions about an informant and trends in the industry. We then asked questions focusing on the processes by which the subsidiary acquires, transforms and exploits external knowledge in the local market. Subsequently, we asked about the factors/ conditions that either facilitate or hinder the development of such capabilities at the subsidiary level. All of our interviews were conducted in either English or the interviewee's native language with an interpreter present when required. During the interview, we adopted a 'court room' style of interviewing, pushing for concrete illustrations to increase the data trustworthiness (Eisenhardt and Graebner 2007). We also promised anonymity to informants to encourage candour.

Of the 62 interviews, 48 were recorded and the recordings transcribed. The other interviews were not recorded either because the informants preferred not to be recorded or there were technical difficulties associated with recording the telephone 


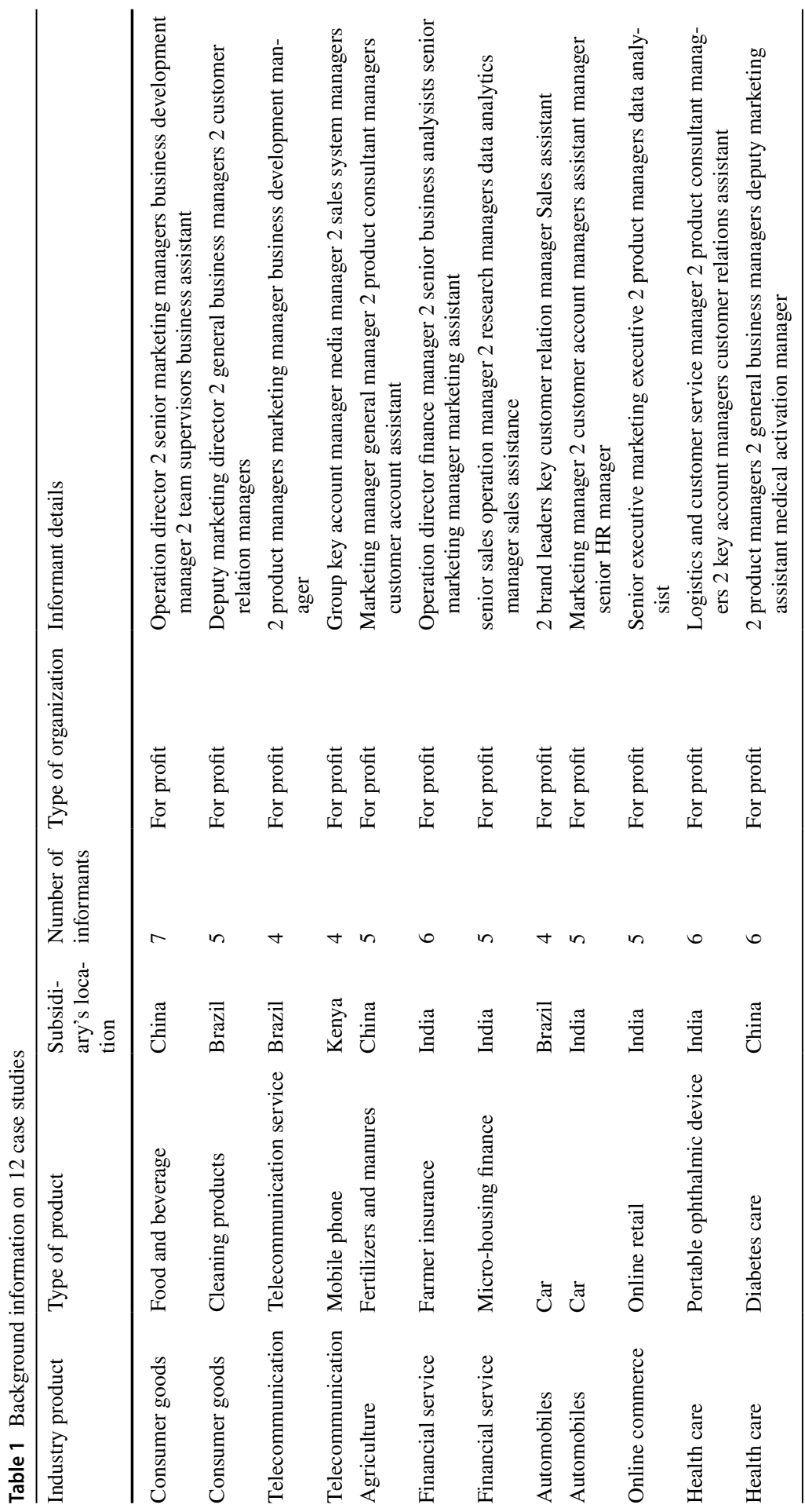


interviews. However, extensive notes were taken during these interviews, recorded verbatim, and then typed up as soon as possible afterwards (Miles and Huberman 1994). We also conducted a "member checking" exercise, sharing our initial findings with informants and requesting their feedback (Lee 1999, p. 52). These interactions helped us to further refine our understanding of the data and achieve a richer understanding of the second order themes and aggregate dimensions. In addition to the interview data, we also collected archival data in the form of published news, magazine articles and research articles published in a wide range of sources. We used the archival data primarily to obtain an in-depth understanding of the challenges faced by MNEs and to gather additional information about the MNEs in our sample.

We treated the 12 MNE subsidiaries as multiple sources for assessing similarities and differences among them, which enabled the generation of emergent theoretical concepts and their interrelationships (i.e., the base for an inductive theory). Following Pettigrew's (1990) guidance for inductive, case-based research, while we approached the organization with a theoretical construct in mind, we did not impose this. Instead, we considered how the detailed evidence gathered in the field might inform existing theory or the construct of absorptive capacity.

\subsection{Data Analysis}

Analysis of the data began immediately after the first interview, adhering to the guidelines consistent with naturalistic inquiry (Lincoln and Guba 1985). These steps helped to guide the focus of further data collection via theoretical sampling (Glaser and Strauss 1967).

\section{(1) Creating provisional categories and first order codes.}

We began our analysis using an open coding approach (Strauss and Corbin 1998) and allowed the data to speak to us (Suddaby 2006) while categorizing and labelling informant statements. We started the open coding process by analytically and systematically breaking down the data. The first author and last author adopted a joint coding approach involving coding the interviews individually sentence by sentence in order to document and evaluate the degree and breadth of support for particular themes across informants. We then compared the coding scheme with one another. Differences of opinion invariably took us back to the interview script for clarification of the text and metaphors comprised in our categories. As we discerned codes that were similar, these were grouped into first-order categories. In an effort to achieve theoretical saturation (Glaser 2004), we continued coding interviews until we could not identify any additional distinct patterns shared amongst our participants. The initial codes covered a range of topics including motivations for searching, interaction with locals, etc. As we progressed in this process, we identified concepts that were "repeatedly present" in, or significantly absent from, our data (Strauss and Corbin 1998, p. 7). We began noticing differences in how informants described key factors in their motivations to search. These initial observations were 
captured in field notes. They later influenced follow up interview questions as we sought to further clarify observed themes, as we cycled between data analysis and consultation with relevant literature. We used the Nvivo software to associate segments of text in each interview and other data sources. We read our data several times according to our evolving understanding (Strauss and Corbin 1998) following a recursive process (Lincoln and Guba 1985). This process enabled us to have an initial classification system to reflect our informants' perspectives. As we discerned codes that were similar, we grouped them into first order categories. Having settled on the initial categorization and definition, we then searched for different and similar themes found across cases by arranging the data into a table, in which the row represented the codes and the columns represented the subsidiary. This process allows for the systematic exploration of differences and similarities across data segments (Strauss and Corbin 1998).

\section{(2) Creating theoretical categories.}

With the development of the first order categories, we started identifying the relationships among the categories and consolidated it to the second-order themes. Specifically, we clustered the first-order codes into higher-order themes to develop, relate, and segregate categories (Strauss and Corbin 1998). For example, we grouped key themes emerging from our data, such as individual perception regarding prior knowledge context and criticality, into a higher-order theme, such as prior knowledge significance. This analysis process not only enabled us to compare and contrast the similarities and differences within and across interviews, but also helped us to make sense of the complex emerging practice and often pointed to areas where further analysis of the complete sample was needed (Strauss and Corbin 1998). To enhance construct validity, we relied on the triangulation of our primary and secondary data. Again, during this process, we went back and forth between emerging theoretical themes and the data. We continued this process until all the data were accounted for and no new categories were produced.

\section{(3) Aggregating theoretical dimensions.}

Once the theoretical categories had been generated, we moved away from axial coding to look for dimensions underlying these categories in an attempt to understand how different categories fitted together into a coherent picture. This enabled us to develop a grounded theoretical framework that linked the various concepts emerging from the data. At this stage, it became apparent that the linkage and process between different constructs started to emerge. We analyzed how these themes related to one another and established different conceptual frameworks that captured these links. Once we had identified a possible framework, we re-examined the data's degree of fit with our emergent theoretical understanding (Becker 1970; Glaser 2004). In an iterative fashion, we analyzed the data by continuously revisiting the consistency between the data and an emergent structure of theoretical arguments (Locke 2001; Miles and Huberman 1994). To further bolster the validity of 
our analysis, we organized a workshop where we displayed and discussed our analysis with our peers with the aim of inducing alternative explanations. Different ideas were discussed and referred back to our informants with the intention to generate alternative explanations. We then used our first draft of this paper to test our interpretation of the events with some of our informants and took their comments into consideration.

Table 2 provides the data structure, including examples of first-order concepts (those meaningful to the informants) and second-order themes (generated by the researchers), that led to the generation of the aggregated dimensions.

\section{Overview of the Findings}

The emergent theoretical model comprises six core concepts and their relationships: prior knowledge significance, unlearning, explorative scanning, knowledge assimilation, exploitative application and organizational context. We first elucidate the six main dimensions that constitute the core of the overall process model, we then present a second layer of findings explicating relationships among these six core dimensions, followed by the complete emergent model.

\subsection{Prior Knowledge Significance}

We found that informants displayed distinct variations in how they perceive the role of path-dependent knowledge in managing their absorptive activities. This prior knowledge significance had two main themes: prior knowledge criticality and prior knowledge context. We discuss in turn each of these elements of the prior knowledge significance and their underlying second-order subtheme.

\subsubsection{Prior Knowledge Criticality}

This facet of prior knowledge significance refers to the informant's beliefs about the degree of importance of the MNE's prior transactional related knowledge, such as operational/marketing efficiency, in terms of its effects on the subsidiary's success. We noted, however, that informants varied in their ascriptions of the importance of the MNEs' path-dependent knowledge and experience to the strategic performance of subsidiaries. Some of our informants expressed a high level of confidence in believing that the MNE's transactional-related knowledge, such as operational efficiency, marketing competency and advanced technological development, was critical to the subsidiary's performance. For example, one of the senior managers indicated that: "What we have (existing knowledge) drives what we do and that's what put us ahead of other competitors, we have better technology, we have better product knowledge, and we also have world class research and development, that is the reason why we are here." Other informants expressed notably less confidence in their belief about the relevance of the MNE's prior knowledge base. In some cases, the existing knowledge was perceived to act as a barrier preventing the firm from recognizing the value of knowledge at the local 


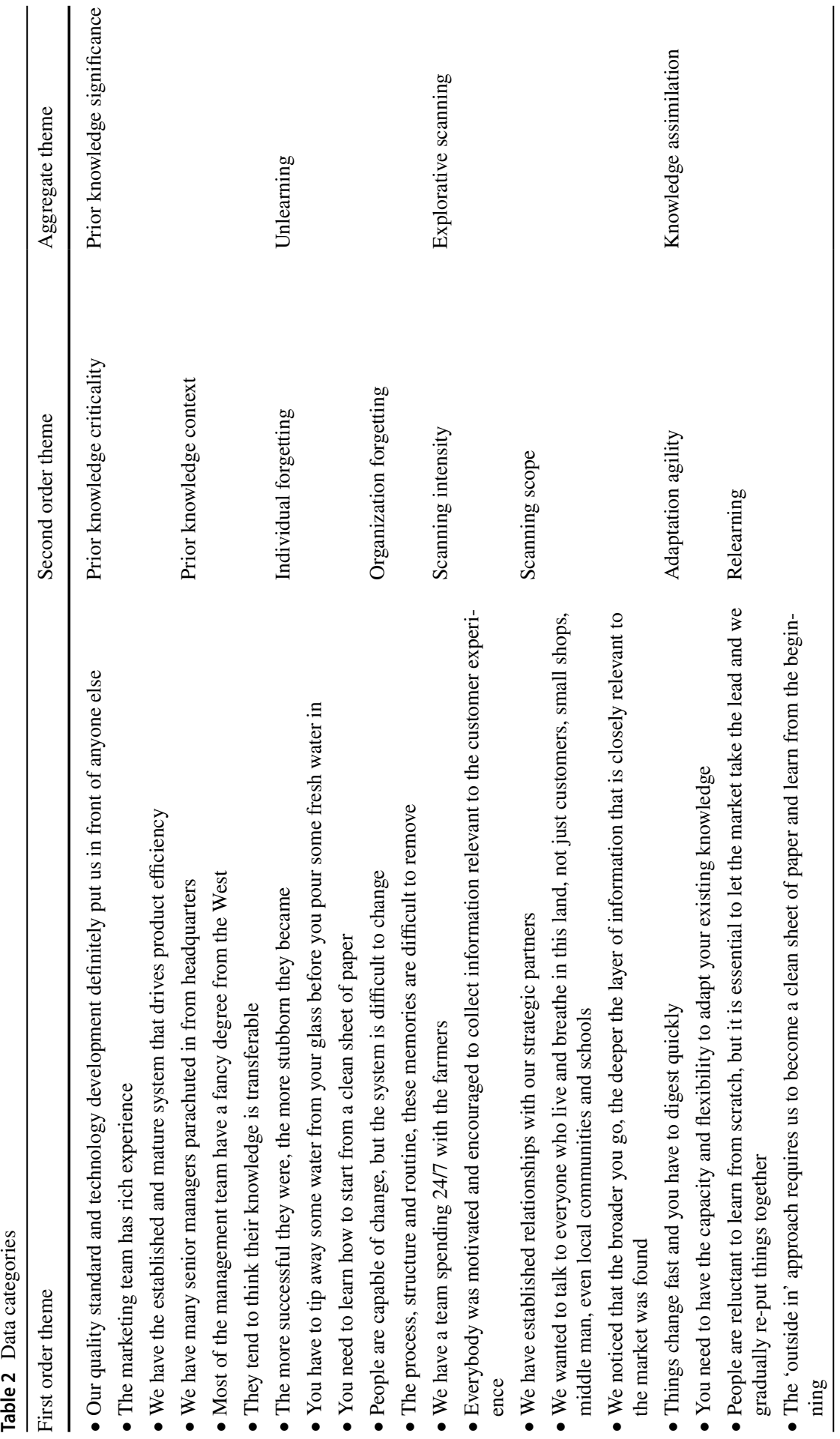




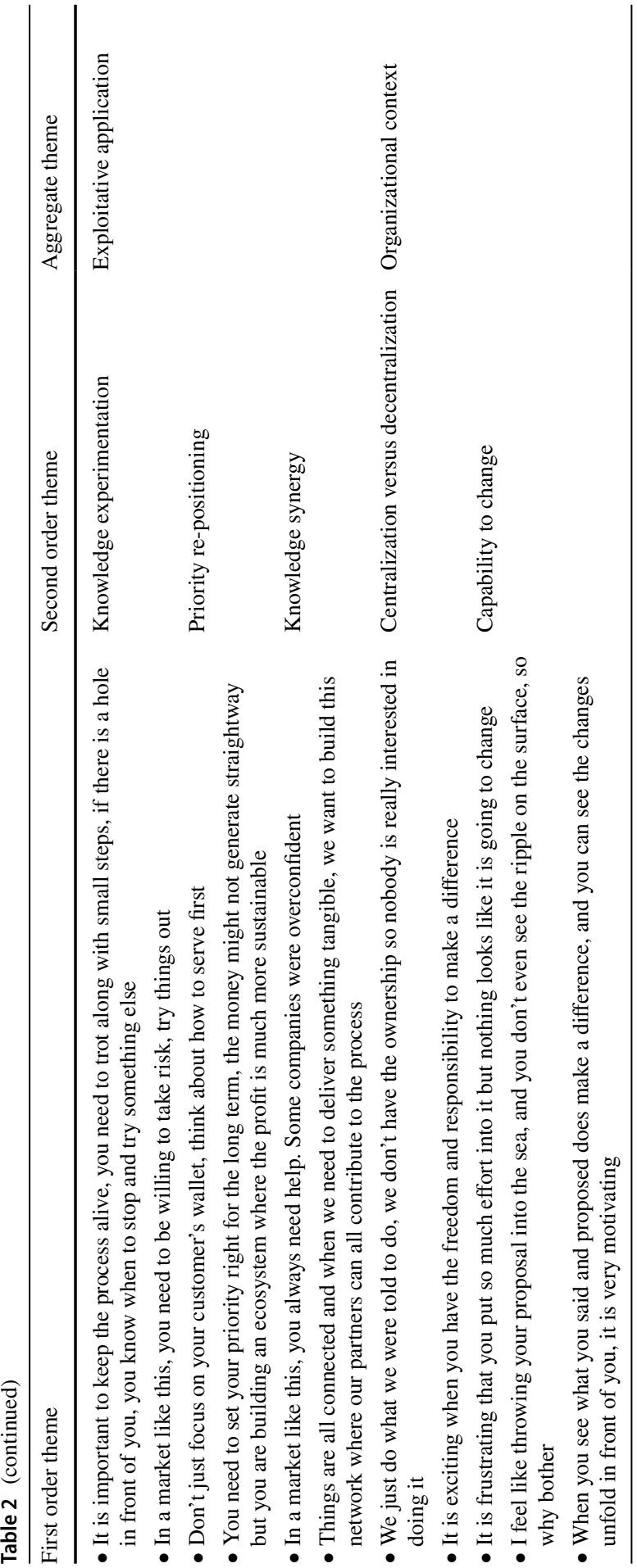


level. The differences in emphasis is evident from the following: "People keep relying on what worked in the past, how the product should be built, how we should promote our product and what the process should be. This mentality made is difficult to open up to other possibilities and ideas. If they can't understand it, they won't accept it."

\subsubsection{Prior Knowledge Context}

This element refers to the informant's understanding and evaluation of the usefulness of context in which prior knowledge was extracted and accumulated. We found notable variations in the perceived importance of context-specific knowledge. A number of informants demonstrated a greater degree of awareness of the limitation of the knowledge that was extracted in a specific context. One of the informants had worked in both Amsterdam and Singapore, when asked about how relevant such experience is in contributing to his understanding of the current market, replied: "Everything that made sense in the past didn't seem to make any sense here. People are naive thinking about the cookie cutter approach. I wish it was that easy. Think about growing fruit in Spain, you simply cannot expect you will have the same results regardless of the location. The sunlight, the humidity, the soil conditions, it all contributes to the final product. Same here, the road conditions, customer's priority, the electricity supply all impact on how customers consume or perceive certain products." Other informants, however, were much more optimistic about the MNEs' existing knowledge regardless of where it was extracted. For example, one of the operational staff commented: "They (senior managers) like the copy and paste approach with a minimal adjustment and then wish for the best. They overestimate their abilities. We have managers who only know how to promote and how to make product with a certain budget and a certain channel. I would assume that it worked very well in the past, but we keep telling them that you have to think about the infrastructure and customers here. They rarely listen to us."

\subsection{Unlearning}

Unlearning captures those activities and beliefs that confer an ability to unlearn or relinquish existing assumptions and knowledge. Unlearning occurred at the individual and organization levels.

\subsubsection{Individual Forgetting}

This element refers to the individual level of conviction or willingness deliberately to forget prior knowledge and experience. There was a consistent pattern in the respondents' perception regarding the role of path-dependent knowledge associated with the degree of unlearning. A number of informants noted that personal ability to unlearn what was already known from past experiences is the key driver to improving the firm's ability to identify and assimilate external knowledge. One informant highlighted "You often get people with the western MBA degree or foreign education, the more successful they were in the past, the more stubborn they are now listening to other or different voices. If you don't tip away some of the water in your 
glass, you can never pull the fresh water in." Other informants from different subsidiaries who have successfully established their businesses showed a marked tendency to value the unlearning. This is reflected in the following observation, "You need to have people who are open-minded and willing to take the new information in, or at least willing to understand the new context, even though is collides with their previous experience. You have to know how to become a clean sheet first."

\subsubsection{Organization Forgetting}

This level of unlearning refers to the organizational level of conviction or willingness purposely to eliminate old/existing knowledge, beliefs and routines. Across the MNEs, although some subsidiaries displayed a high level of individual unlearning, they were constrained by unlearning at the organizational level. This is reflected in the following vignette: "It is like an ongoing battle. You have to fight with the existing system. It is very difficult to change or challenge the system if companies are trapped in the past glory." On the other hand, other informants from different subsidiaries characterized their search abilities and behaviours that might result from organizational forgetting: "We came to this market with a fresh and clear mind. We knew it is simply impossible to scale up with what we had, so we were fully prepared to bend, stretch and in some cases, completely start from scratch." Information gathered from lower-echelon employees of the same organization confirmed this statement.

Comparing the subsidiaries that demonstrated a different level of unlearning, we noted that they differ in their abilities to scan, internalize and apply external knowledge. We next discuss the rest of the constructs that emerged from our data and display the linkages between unlearning and these constructs.

\subsection{Explorative Scanning}

Our data revealed that beliefs about unlearning were associated with differences in effort and scope of explorative scanning aimed at recognizing and acquiring external knowledge. This element had two main themes: scanning intensity and scanning scope. We discuss each of these elements of explorative scanning next.

\subsubsection{Scanning Intensity}

This facet of explorative scanning refers to the amount of time and effort subsidiaries invest in recognizing and collecting external knowledge. We noted various patterns among subsidiaries in their efforts to search for new information and knowledge. For instance, one of the informants from a company that successfully penetrated the market stated: "We wanted to build a team where everyone has the responsibility to understand our customers, no matter whether you are an engineer or from a research team. We spent everyday understanding their (customer) behaviour, their thoughts and priorities." On the other hand, we found that the scanning intensity was much lower for some subsidiaries. For example, one of the informants stated: "We have 
our marketing people doing market research here. The information is scare here and it is difficult to gather what is useful to you."

\subsubsection{Scanning Scope}

This mode of scanning behaviour captures the tendency of informants to conduct scanning by expanding the searching scope in order to collect information. Scanning scope thus represents not just time and effort devoted to collect information, but the tendency actively to seek information beyond the conventional boundary. For example, one informant indicated, "In small villages in China, local farmers normally like to hang out after dinner, everybody sat under the trees, with a cup of tea and handheld fan, they like to chat about all sorts of stuff, we like to be part of the conversation and to see what crops they like to grow and why, what fertilizer they use, what concerns them the most, etc." On the other hand, some MNEs that were struggling with obtaining local knowledge tend to be rather passive in their searching and have narrower boundaries in their information search tendencies. This is reflected by an informant as follows: "We went to trade shows and a workshop organized by the local government and commercial bodies where we can gain more understanding about customers."

\subsection{Knowledge Assimilation}

We found clear variations in how external knowledge is assimilated and institutionalized at the subsidiary level. This had two main themes: adaptation agility and relearning.

\subsubsection{Adaptation Agility}

This aspect of transformative learning captures the firm's ability to quickly transform/adapt external knowledge. The emphasis here is less on maintaining assimilated knowledge over time and more on the firm's ability to assimilate quickly external knowledge. Such agility was described as the key to generating new insights, enriching the firm's existing knowledge base and being responsive to the rapidly changing external environment, as represented in the following description: "We cannot just keep it (external knowledge) in the pot. In a developed country, everything moves slowly, here, the ground shifts underneath our feet every day. You have to be able to quickly turn it (external knowledge) into something tangible. When the opportunity arises, you have to catch it quickly." In contrast, some informants showed the opposite way of internalizing external knowledge highlighting the limitation of slow response to transform external knowledge: "The digesting process is too long. It takes a long time for people to understand, accept and finally replace the old beliefs. Our competitors were able to seize the opportunities quickly and we left with some dust." 


\subsubsection{Relearning}

While unlearning describes subsidiaries' capability to discard old/existing knowledge and routines, this element describes the way in which companies are able to assimilate external knowledge through relearning and developing new knowledge. There was a consistent theme across different informants highlighting the importance of relearning. Subsidiaries that demonstrated a high degree of unlearning tend to associate closely with the firm's ability of relearning. "Everything is new here; we want our people not only to feel comfortable to question our assumptions and beliefs, but also feel comfortable and be supported to digest it and transform it to new knowledge." However, as relearning is often associated with additional costs and investments because of the need to develop new capabilities, knowledge and their constituent routines, in some cases, some subsidiaries revealed a relatively low tendency to engage in relearning. "This is the most frustrating part. We know what needs to be done but when it comes to the practical implementation, nothing happened. It's not going to change by itself, people like to see the results, but they don't like to invest in the process. So all the hard work we did in the past was a waste of time."

\subsection{Exploitative Application}

Our data analyses suggested a prominent focus on how knowledge was applied to create the new product or services for the market. Exploitative application emphasized the process of developing new knowledge that assists the firm in converting the acquired knowledge with the refinement and extensions of existing product or service. Three distinct forms of exploitation application were evident in the data: knowledge experimentation, knowledge re-positioning and knowledge synergy.

\subsubsection{Knowledge Experimentation}

This refers to 'learning by doing' attempts made by subsidiaries in order to experiment with new ideas. We noted a consistent pattern of a 'trial and error' approach in some subsidiaries. For some firms, this mode was seen as the ability to 'test' the market, as exemplified in the following observation: "The solutions that worked in the West will not work here. We have a very limited internet access and electricity supply, no established logistics service. What are you going to do? We tried many ways to connect with them (customers). Currently we set up a little stall at the local market; customers can come in and see our catalogue, and give us a number and their location, so we can deliver it to them. We are still trying to improve the whole process. The process needs to be alive and have the ability to keep changing it and improving it." In other subsidiaries, we found that the level of experimentation was rather low. One of our informants stated: "We don't want to take too many risks because there are so many uncertainties here. You don't know what the responses and outcomes would be, so we wanted to be cautions and fully prepared when it's ready." 


\subsubsection{Knowledge Re-positioning}

This element captures those activities that involve re-positioning knowledge to build up capacity for the benefit of customers, rather than heavily focusing on capitalizing the resources and knowledge for short-term profit. The emphasis here is less on generating profit in the short term and more on using knowledge to go beyond the capitalization to generate new insights and ideas to create capacity for customers. This is represented in the following description: "Some organizations get quite impatient, once they understand the market, they were rather eager to make a sale. You need to think about the potential this market might bring and use what you know to cultivate and stimulate that potential." Some informants demonstrated a high level of understanding of re-prioritizing the knowledge source in order to generate value for customers, and then to capture the value from the market, a tendency reflected in the following statement: "There was no infrastructure for refrigerated milk collection, farmers do not have the facilities and resources to either store or transport milk, so lots of milk ended up wasted. If your priority was to squeeze as much profit as you can from the farmers, then you can only go so far. We created a refrigerated collection centre in the local villages where farmers have great accessibility, this reduced the milk waste and also helped farmers to get more benefits from their product. We also created a free brochure and training programme to educate our farmers in the right process. We can see the steady positive progress month by month." In contrast, others were much more eager to generate profit. For example, one senior manager described his intention: "We are not doing a charity here and everyday want to make profit. So, you have to seize all the opportunities while you can. They (customers) don't have that much money to spend, so how can we get them to spend on us and not others is the key."

\subsubsection{Knowledge Synergy}

An essential facet of knowledge synergy was the creation of a social context wherein the organization and its local formal and informal partners were actively engaged to exploit new ideas. This involves a collective effort in solving the shared-understanding on a particular issue. There is a consistent pattern among subsidiaries that have successfully penetrated the local market who tend to be much more pro-active in collaborating with institution partners including customers, supporting companies, universities and local communities that directly or indirectly facilitate the knowledge exploitation process. For instance, one informant stated: "We were struggling over coming up with new ways to transport our drugs to different villages. We couldn't afford to build up our own logistic system and have our own couriers. We have a 'health clinic' day where we offer free health advice and consultation to local people. And we always piggy-back such sessions to seek advice from local people. One of our customers came to us after the session and told us that he has a son that delivers drinks to the villages. And the gaps in between the bottles in the crates can hold small medicine vials, and this may help us to reach the people from different villages in a cost-effective way." In contrast, other informants tend to collaborate with limited ties in order to apply external knowledge. They either focused on a few 
partners such as government, strategic alliances or largely relied on themselves to exploit the market.

\subsection{Organizational Context}

Our analysis indicated that different performance linked with learning processes of absorptive capacity was associated with the difference in the MNEs' organizational context.

\subsubsection{Centralization Versus Decentralization}

This element of organization context refers to organizational structure such as centralization and decentralization. There is a highly consistent theme across all cases that the organizational structure varies in degrees that affect subsidiary motivation in recognizing, transforming and applying external knowledge in the local market. We found that subsidiaries' motivation in MNEs that have a centralized organization structure is much lower than MNEs that have a decentralized organization structure, as described by one of the informants: "They (headquarters) like to remote control our actions. Most of them probably have never even been to the small villages of Kenya. They don't know the place, they don't know the people, they don't know what situations we are in, and somehow they think they are in a better position to tell us what we should and shouldn't do. Our hands were bound and we couldn't really do what we wanted to do, so why bother." In contrast, one subsidiary informant from an MNE with a decentralized structure, stated that "We felt that we are the owner of this challenge, we have the freedom and responsibility to solve the problem."

\subsubsection{Capability to Change}

This element refers to the subsidiary's capability to change, to re-configure its resource and knowledge base in order to respond to the changing market. Throughout the interviews, a consistent pattern emerged showing that these subsidiaries' capability of change represented how well the external knowledge was recognized, assimilated and acted upon in a complex and different institutional environment. Surprisingly, we also noted that such variation is also closely linked to the centralized and decentralized organization structure within the MNEs. In some cases there was a view that fixed beliefs, organizational routines and processes can diminish a subsidiary's motivation at different levels of the learning process of absorptive capacity. Lack of flexibility in the firm's actions and behavior to cope with new knowledge, transform it and apply it to commercial ends is closely associated with the subsidiary's ability to scan, transform and exploit external knowledge in the local market. For example, one informant stated: "The whole process just wears you out. It takes an age for them (headquarters) to respond and you have to go through a chain of command and layers of persuasion, it is like why do I have to go through all this trouble and try to convince you what is best for this company?" On the other hand, some subsidiaries demonstrated that a capability to change is closely associated with 
a high motivation level. This is reflected in the following quote: "Things change so quickly here. When you see an opportunity, you need to work quickly to seize that opportunity. You get to see the changes and results unfolding in front of you, it was very exciting."

\section{Discussion}

This paper explores the determinants of absorptive capacity in subsidiaries by examining how MNE subsidiary managers operating in emerging markets, recognize, assimilate and apply external knowledge. We also explore how different patterns lead to variation in subsidiary absorptive capacity. Six constructs emerged from the data: prior knowledge significance, unlearning, explorative scanning, transformative learning, exploitative application and organization context. Each construct exhibited common forces with variation in their interplay and importance. Through the iteration of data and theory, we developed the model shown in Fig. 1, which presents a process framework that suggests the dynamic relationships among the emergent concepts underlying absorptive capacity. To explore these relationships in more depth, we next present another layer of findings that show how specific elements of the model are linked.

Our analysis suggests that managers who show a greater tendency to recognize, transform and apply external knowledge are managers who tend to perceive that their prior knowledge and experience is not as beneficial as that of their employees in the host country. This perception tended to encourage these managers to unlearn and engage more intensively in localized learning. Our data indicated that these managers tended to be much more willing to listen to the lower echelon employees from the local market, were more active in building local external networks, and more intensive in searching local knowledge. The focus of these managers was to engage in intensive and broad knowledge scanning, rather than seeking relevant knowledge from their prior knowledge base and from their traditional business partners. The unlearning construct that emerged from our data contradicts the assumption that recognizing and assimilating new knowledge requires prior knowledge (Cohen and Levinthal 1990). The accumulation and development of the MNE's prior knowledge and experience are imprinted by the home country's culture (Bhagat et al. 2002; Björkman et al. 2007). Consequently, a subsidiary may lack the ability to recognize and comprehend valuable information in the host country where the institutional environment is radically different from the home country. Therefore, when the subsidiary is exposed to a radically different institutional setting, its ability to purposefully forget and deliberately attempt rethinking positively contributes to the firm's subsequent activities in recognizing and assimilating external knowledge. This is consistent with scholars who have highlighted that the importance of unlearning is associated with the firm's ability to create and apply new knowledge and new knowledge structures (Cepeda-Carrion et al. 2012; Lavie 2006; Tsang 2008; Tsang and Zahra 2008). This leads to our first proposition: 


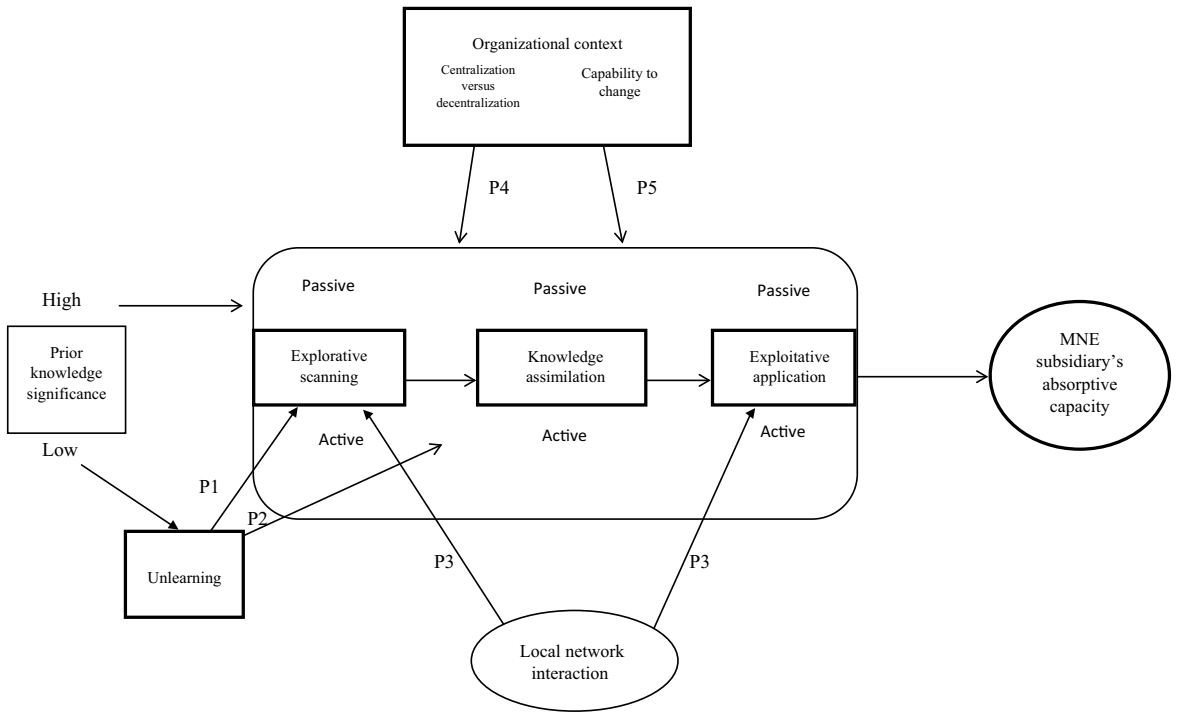

Fig. 1 Processes underlying MNE subsidiary absorptive capacity

Proposition 1: Unlearning will be positively associated with the explorative scanning process of absorptive capacity for MNE subsidiaries operating in different and complex institutional environments.

While we analyzed the fine-grained process of absorptive capacity, we also found that path-dependent knowledge tends to prevent the subsidiary from assimilating external knowledge. We noted that the MNE's mind-set, routines, and knowledge can act as an inflexible barrier. The relational analysis of our data suggests that the beliefs and actions about unlearning are closely related to MNE subsidiaries' ability to relearn. This is reflected in the following observation:

"It is completely a different kind of game here and we have to click on the reset button and start everything from ground up. You would never know what matters to our customer the most regarding the fridge is not about temperature, is not about different cooling settings, it's about have a cord that won't be chewed and damaged by the rat. So, forget about what you know, forget about all the assumptions you have, tip all that away in a safe place and start to understand and learn this world around you."

Managers that demonstrated a strong attitude toward unlearning tended to be more willing to invest in developing new resources, capability and routines. Our data indicated that the established mind-set, routines, and knowledge may need to be flexibly adopted, and in some cases abandoned in order to improve the speed to market, quality, and overall success of the new product or process, because a 'one size- fits-all' approach is not likely to be applicable in the innovation process, particularly in host countries where the institutional setting is considerably different from the West. As illustrated by our findings, unlearning is significantly 
linked to the adaptation agility and relearning elements of the transformative learning process of absorptive capacity. This leads to our second proposition:

Proposition 2: Unlearning will be positively associated with the knowledge assimilation stage of absorptive capacity for MNE subsidiaries operating in different and complex institutional environments.

From analysis of the interviews a consistent pattern emerged showing that the capability of subsidiaries to engage in continuous interaction with local external stakeholders represented how well external knowledge was recognized and acted upon in a complex and different institutional environment. We found that MNE subsidiaries that have better access to local knowledge tend to be more active and place greater emphasis on building relationships with a much wider set of local partners. The knowledge connectivity resulting from a broad network interaction diffuses the development of new knowledge, which is crucial for MNEs operating in a new and complex institutional environment, where the firm's path-dependent knowledge adds limited value in this setting.

Conversely, companies that were less successful in recognizing and collecting external knowledge tended to be more passive and either apply the external knowledge in isolation or apply it in a limited network with government and strategic alliance partners. Similar findings occur with exploitative application, where subsidiaries showing a tendency to work closely with formal and informal business partners tended to be more successful in exploiting external knowledge. Subsidiaries showing a greater tendency towards local network interaction had better opportunities to exploit external knowledge in the host country. This is consistent with scholars who highlight the importance of local networks, particularly nontraditional partners that provide information on the local context, legitimacy and access to needed resources (Cano-Kollmann et al. 2016; Fan et al. 2015; London and Hart 2003; Rondinelli and London 2003; Simanis and Hart 2006).

This leads to our third proposition:

Proposition 3: Local formal and informal network interaction will be positively associated with the explorative scanning and exploitative application stage of absorptive capacity for MNE subsidiaries operating in different and complex institutional environments.

We found two organization contexts that influence absorptive capacity of the subsidiary. One context is the firm's structure, which was closely associated with the subsidiary's ability to recognize, assimilate and apply external knowledge. We found that the subsidiary's motivation is positively associated with a decentralized organizational structure. In contrast, where the subsidiary demonstrated a low or passive level of absorptive capacity this tended to be closely linked with organizations that have a centralized structure. Such a structure not only delays the decision-making process, but also curbs the subsidiary's flexibility and initiative in collecting, transforming and applying external knowledge. This is in accordance with the view that decentralization intrinsically predispositions and rewards initiatives to decipher the potential value of new knowledge (Gupta and 
Govindarajan 2000). This is particularly important in the host country where the institutional environment is radically different from the home country. The greater subsidiary autonomy also provides more freedom to assimilate the external local knowledge in the local market (Chang and Harrington 2000; Menon and Veradarajan 1992).

This leads to our fourth proposition:

Proposition 4: A decentralized (centralized) governance structure will be positively (negatively) associated with absorptive capacity of MNE subsidiaries operating in different and complex institutional environments.

We also noted that although a number of firms made active attempts to acquire local knowledge, they were less active in transforming and applying such acquired knowledge. It became apparent that the subsidiary's ability to internalize and apply external knowledge was hampered by established rigorous routines and processes. Our analysis suggests that the subsidiary's ability to reconfigure its internal and external resources and respond quickly to the market by reconfiguring its processes and resources tends to have a positive impact on its ability to transform external knowledge and exploitive learning. Several scholars have argued that the firm's ability purposefully to create, extend or modify its resource base, enables the firm to adapt proactively, for example, by developing new technology, responding to competition, gaining critical mass and serving evolving customer needs (Augier and Teece 2007; Schilke 2014). Evidence in the literature shows that dynamic capabilities often highlight a highly rational, analytical, stable process with predictable outcomes (Hofer and Schendel 1978; Lorange and Vancil 1976), whereas dynamic capabilities in a high velocity market should be simple, highly experiential and fragile processes with unpredictable outcomes (Eisenhardt and Martin 2000). Our findings resonate with this perspective, such that when operating in a different and complex institutional environment, the subsidiary should have the capability to refocus and reconfigure its internal and external resources to be flexible and highly experiential.

This leads to our final proposition:

Proposition 5: The capability to refocus and reconfigure its internal and external resources in a flexible and highly experiential manner will be positively associated with absorptive capacity of MNE subsidiaries operating in different and complex institutional environments.

\section{Conclusion}

We have examined how managers working in a different and complex institutional environment differ in their attitudes towards learning, unlearning and adaptation of local business practices. This work extends and bridges various prior studies that comprise the literature on absorptive capacity (e.g., Cohen and Levinthal 1990; Lane and Lubatkin 1998; Lane et al. 2001; Uhlenbruck et al. 2003; Zahra and George 2002). While much of the extant literature focuses on the MNE's parent company 
or network knowledge, this study places more emphasis on the subsidiary's external embeddedness and its ability to generate local knowledge assets in the host country. Although prior studies have provided important insights into the absorptive capacity of MNEs, as far as we are aware this is the first study to detail the process of how managers from MNEs' subsidiaries operating in a different and complex institutional environment perceive learning, unlearning and business adaptation in the development of absorptive capacity. The main outcome and contribution of this study is an inductive process model that not only shows that managers differ in their ability to absorb local knowledge, but also shows how those differences relate to the process by which the external knowledge was collected, assimilated and applied. In the course of our developed framework, several insights with theoretical implications emerged, especially managerial cognition, unlearning, scanning activities and dialectic interaction with local informal partners.

Mere exposure to external knowledge does not necessarily guarantee knowledge absorption. Although the literature shows that managerial cognition is consequential in a firm's strategic context (Tripsas and Gavetti 2000), there is limited evidence on how managerial cognition is related with subsequence knowledge search and actions, particular in a radically different business environment which contradicts the knowledge accumulated in the past. This study identifies and explicates key actions and practices that have previously been largely treated as implicit in the discussion of absorptive capacity at subsidiary managerial level. As such, it enriches the micro-processes of absorptive capacity. With formal institutional voids in emerging economies, this leads to socioeconomic activities being predominantly controlled by informal institutions (de Soto 2000). The findings further suggest that the construct of absorptive capacity requires revision in order to accommodate unlearning as a new capability in the context where MNE subsidiaries operate in a different and complex institutional environment. Our findings challenge the notion that a firm possesses the relevant prior knowledge that can guide it to recognize valuable external knowledge (Cohen and Levinthal 1990; Lane and Lubatkin 1998; Lane et al. 2001; Uhlenbruck et al. 2003). We noted that such prior knowledge did not generate valuable knowledge that can benefit subsequent activities. On the contrary, managers that draw heavily on their prior knowledge were more likely to configure incorrect assumptions and reach inaccurate conclusions regarding future search activities, leading to a detrimental experience effect on the firm's absorptive capacity. Such prior knowledge continues to surface consistently and hinder knowledge assimilation. Our findings indicate that unlearning assists the managers in eliminating old beliefs, logics and routines that have not been helpful in enhancing absorptive capacity capability. This is consistent with researchers linking the concept of unlearning with absorptive capacity (e.g., Cepeda-Carrion et al. 2012; Lavie 2006; Tsang 2008). Therefore, we propose unlearning as an enabler of localized learning for the MNE's subsidiary operating in an emerging economy where the host country's cultural, geographical, religious, ethnic and linguistic features are radically different from the home country.

Our findings also link unlearning with subsequent knowledge search action. Our findings suggest that action patterns that involve explorative scanning, knowledge assimilation and exploitative application in dealing with external knowledge 
are the bases on which organizational competence can develop. Evidence revealed that unlearning affects managers' efforts in engaging in localized learning. Further, findings showed that managers are more likely to access and exploit external local knowledge when they engage in proactive explorative scanning in terms of scanning intensity, scope and interaction. However, this proactiveness is largely influenced by the degree of unlearning, which further influences managers' action in their ability to assimilate and exploit external knowledge. In particular, we found that experimentation and co-value creation with local formal and informal partners is positively associated with the ability to apply the external knowledge to commercial ends. This is consistent with scholars who have emphasized that continuous experimentation and local knowledge connectivity are the main mechanism to address a profound institutional uncertainty (e.g., Cano-Kollmann et al. 2016; Cantwell et al. 2010; Teece 2014).

We also contribute to theory by highlighting the organization context that determines the subsidiary's absorptive capacity. Critical to the advancement of the absorptive capacity literature is to move away from a structural perspective to view absorptive capacity as more of a dynamic capability that affects future knowledge creation (Lane et al. 2006). From our findings, we argue that centralization/decentralization and capability to change are critical internal drivers of absorptive capacity. Our analysis shows that an entrepreneurial approach that focuses more on opportunities than on opportunism, both inside the firm and also linking the firm to external partners (Teece 2014) can also drive the innovation outcome. This is consistent with research that accentuates the firm's capability to change in a rapidly evolving environment and plays a crucial role in contributing to the firm's sustainable competitive advantage (Augier and Teece 2007; Schilke 2014).

The study's findings have implications for how MNEs develop and nurture the absorptive capacity of their subsidiaries. Our study shows that in a rather less developed and complex institutional environment, managers through their meaningful actions, can create a high level of absorptive capacity. For example, the concept of unlearning, explorative scanning and local formal and informal network interaction can help to bridge insights from the micro-level of analysis (e.g., about different learning processes and network scope). To actively develop the subsidiary's absorptive capacity requires a re-evaluation of the prior knowledge base and more active engagement in explorative learning by immersion in a local network. This requires managers to be more aware of the role of unlearning in order to update the knowledge base that was extracted from a different context.

Our findings also lend further support to the assertion that the subsidiary is no longer a passive recipient of knowledge from MNE headquarters. Rather, the subsidiary can, perhaps more importantly, act as an active guide for localized knowledge search and actions that change the power balance in the system. By doing so, the subsidiary can build strong links with corporate and local external stakeholders such as suppliers, customers and governments. 


\subsection{Limitations and Future Research}

The study has certain limitations that constrain the interpretation and application of the findings. The first limitation is the emerging market setting, which by definition limits generalizability. Like any other process research (Mohr 1982), this study focuses on understanding the causal dynamics of a particular setting, as opposed to providing information on the generalizability of the findings of other settings. A trade off was also made between having a rich source of detailed data in a particular and relatively under-researched context and broad institutional settings that would permit generalization of findings. MNE subsidiaries were the primary source for our data collection, it would be productive for future studies to use multiple data sources, such as customers, suppliers and local communities, in order to provide further insights. Another limitation is our focus on informant accounts via interviews as our main source of data. Although we guarded against bias, as in any qualitative research, that concern lingers.

This study has focused on the process of absorptive capacity. Future studies that bring insights from research into the building of a local ecosystem that support and nurture innovation would help to provide deeper insights into the micro processes underlying the development of absorptive capacity. Further research could also investigate how psychological aspects of individual managers, personal traits and emotional intelligence affect such learning processes. A follow-up to this study would perhaps involve a longer time spent inside subsidiaries more systematically observing the micro-level actions and interactions in which managers and other organization members engage when facing situations in real time. Future work would also benefit from gathering information about country markets, and manager's age and gender and investigate how such variables impact ACAP process development. Compared to MNE subsidiaries, local firms are more independent and find it easier to interact with local networks. Therefore, future studies on how MNEs' subsidiaries can overcome the hierarchical structure and be more embedded in local networks will be crucial to improving our understanding of knowledge connectivity in the host country. The interplay between external formal and informal network partners and the MNE's subsidiary also poses new questions, which IB scholars have only recently started to explore. The knowledge connectivity between the subsidiary and its local external network would steer the conversation towards a coevolutionary view of the dynamic relationships between the MNE and its location. Our study provides a promising starting point for further research that moves beyond an outcome-driven approach and examines how the process was managed.

Open Access This article is distributed under the terms of the Creative Commons Attribution 4.0 International License (http://creativecommons.org/licenses/by/4.0/), which permits unrestricted use, distribution, and reproduction in any medium, provided you give appropriate credit to the original author(s) and the source, provide a link to the Creative Commons license, and indicate if changes were made. 


\section{References}

Almeida, P., Song, J., \& Grant, R. M. (2002). Are firms superior to alliances and markets? An empirical test of cross border knowledge building. Organization Science, 13(2), 147-161.

Andersson, U., Dellestrand, H., \& Pedersen, T. (2014). The contribution of local environments to competence creation in multinational enterprise. Long Range Planning, 47(1-2), 87-99.

Augier, M., \& Teece, D. J. (2007). Dynamic capabilities and multinational enterprise: Penrosean insights and omission. Management International Review, 47(2), 175-192.

Barkema, H. G., \& Drogendijk, R. (2007). Internationalising in small, incremental or larger steps? Journal of International Business Studies, 38(7), 1132-1148.

Bartlett, C. A., \& Ghoshal, S. (1989). Managing across borders: The transnational solution. Boston: Harvard Business School Press.

Bartlett, C. A., \& Ghoshal, S. (1990). The multinational corporation as an interorganizational network. Academy of Management Review, 15(4), 603-626.

Becker, H. S. (1970). Sociological work: Method and substance. Chicago: Aldine.

Bhagat, R. S., Kedia, B. L., Harveston, P. D., \& Triandis, H. C. (2002). Culture variations in the cross border transfer of organizational knowledge: an integrative framework. Academy of Management Review, 27(2), 204-221.

Birkinshaw, J. (1998). Corporate entrepreneurship in network organizations: How subsidiary initiative drives internal market efficiency. European Management Journal, 16(3), 355-364.

Birkinshaw, J., \& Morrison, A. (1995). Configurations of strategy and structure in subsidiaries of multinational corporations. Journal of International Business Studies, 26(4), 729-754.

Björkman, I., Stahl, G. K., \& Vaara, E. (2007). Culture differences and capability transfer in cross border acquisitions: The mediating roles of capability complementarity, absorptive capacity and social integration. Journal of International Business Studies, 38(4), 658-672.

Bouquet, C., \& Birkinshaw, J. (2008). Managing power in the multinational corporation: How low-power actors gain influence. Journal of Management, 34(3), 477-508.

Buckley, P. J., \& Casson, M. (1976). The future of the multinational enterprise. Basingstoke: Macmillan.

Caligiuri, P. (2014). Many moving parts: Factors influencing the effectiveness of HRM practices designed to improve knowledge transfer within MNEs. Journal of International Business Studies, 45(1), $63-72$.

Cano-Kollmann, M., Cantwell, J., Hannigan, T. J., Mudambi, R., \& Song, J. (2016). Knowledge connectivity: An agenda for innovation research in international business. Journal of International Business Studies, 47(3), 255-262.

Cantwell, J. A. (1989). Technological innovation and multinational corporations. Oxford: Blackwell.

Cantwell, J. (2014). Revisiting international business theory: A capabilities-based theory of the MNE. Journal of International Business Studies, 45(1), 1-7.

Cantwell, J., Dunning, J., \& Lundan, S. (2010). An evolutionary approach to understanding international business activity: The co-evolution of MNEs and the institutional environment. Journal of International Business Studies, 41(4), 567-586.

Caves, R. E. (1971). Industrial Corporation: The industrial economics of foreign investment. Economica, $38(149), 1-27$.

Cepeda-Carrion, G., Navarro, J. G. C., \& Martinez-Caro, E. (2012). Improving the absorptive capacity through unlearning context: An empirical investigation in hospital-in-the-home units. Service Industries Journal, 32(9), 1551-1570.

Chang, M. H., \& Harrington, J. E. J. (2000). Centralization vs decentralization in a multi-unit organization: A computational model of a retail chain as a multi-agent adaptive system. Management Science, 46(11), 1427-1440.

Cohen, W., \& Levinthal, D. (1990). Absorptive capacity: A new perspective on learning and innovation. Administrative Science Quarterly, 35(1), 128-152.

De Soto, H. (2000). The mystery of capital: Why capitalism triumphs in the West and fails everywhere else. New York: Basic Books.

Delany, E. (1998). Strategic development of multinational subsidiaries in Ireland. In J. Birkinshaw \& N. Hood (Eds.), Multinational corporate evolution and subsidiary development (pp. 239-267). New York: St. Martin's.

Doz, Y., Santos, J., \& Williamson, P. (2001). From global to metanational. Boston: Harvard Business School Press. 
Eisenhardt, K. M. (1989). Building theories from case study research. Academy of Management Review, 14(4), 532-550.

Eisenhardt, K., \& Graebner, M. (2007). Theory building from cases: Opportunities and challenges. Academy of Management Journal, 50(1), 25-32.

Eisenhardt, K. M., \& Martin, J. A. (2000). Dynamic capabilities: What are they? Strategic Management Journal, 21(10-11), 1105-1121.

Fan, D., Cui, L., Li, Y., \& Zhu, C. J. (2015). Localized learning by emerging multinational enterprises in developed host countries: A fuzzy-set analysis of Chinese foreign direct investment in Australia. International Business Review, 25(1), 187-203. (Part A).

Fang, E., \& Zou, S. (2010). The effects of absorptive and joint learning on the instability of international joint ventures in emerging economies. Journal of International Business Studies, 41(5), 906-924.

Feldman, J. M. (1986). A note of the statistical correction of halo error. Journal of Applied Psychology, 71(1), 173-176.

Felin, T., \& Hesterly, W. S. (2007). The knowledge-based view, nested heterogeneity, and new value creation: philosophical considerations on the locus of knowledge. Academy of Management Review, 32(1), 195-218.

Fosfuri, A., \& Tribó, J. (2008). Exploring the antecedents of potential absorptive capacity and its impact on innovation performance. Omega, 36(2), 173-187.

Gioia, D., Corley, K., \& Hamilton, A. (2013). Seeking qualitative rigor in inductive research: Notes on the Gioia methodology. Organizational Research Methods, 16(1), 15-31.

Glaser, B. G. (2004). Naturalist inquiry and grounded theory. Qualitative Social Research, 5, 23-32.

Glaser, B., \& Strauss, A. (1967). The discovery of grounded theory. Hawthorne: Aldine Publishing Company.

Gupta, A. K., \& Govindarajan, V. (2000). Knowledge flows within the multinational corporation. Strategic Management Journal, 21(4), 473-496.

Hammond, A. L., Kramer, W. J., Katz, R. S., Tran, J. T., \& Walker, C. (2007). The next four billion: Market size and business strategy at the base of the pyramid. Washington: World Resources Institute and International Finance Corporation.

Hart, S. L., \& Christensen, C. M. (2002). The great leap: Driving innovation from the base of the pyramid. Sloan Management Review, 44(Fall), 51-56.

Harvey, M., \& Buckley, M. R. (2002). Assessing the 'conventional wisdoms' of management for the 21st century organization. Organizational Dynamics, 30(4), 368-378.

Hofer, C. W., \& Schendel, D. (1978). Strategy formulation: analytical concepts. MN: St. Paul, West.

Hymer, S. H. (1960). The international operations of national firms: A study of direct foreign investment, Published PhD Dissertation, Massachusetts Institute of Technology, Cambridge.

Jarillo, J. C., \& Martinez, J. I. (1990). Different roles for subsidiaries: the case of multinational corporations in Spain. Strategic Management Journal, 11(7), 501-512.

Johanson, J., \& Vahlne, J.-E. (1977). The internationalization process of the firm-a model of knowledge development and increasing foreign market commitment. Journal of International Business Studies, $8(1), 23-32$.

Kim, L. (2001). Absorptive capacity, co-operation, and knowledge creation: Samsung's leapfrogging in semiconducters. In I. Nonaka \& T. Nishiguchi (Eds.), Knowledge emergence-social, technical, and evolutionary dimensions of knowledge creation (pp. 270-286). Oxford: Oxford University Press.

Kim, H., Hoskisson, R. E., \& Lee, S. H. (2015). Why strategic factor markets matter: 'New" multinationals' geographic diversification and firm profitability. Strategic Management Journal, 36(4), 518-536.

Kostova, T., Roth, K., \& Dacin, M. T. (2008). Institutional theory in the study of multinational corporations: A critique and new directions. Academy of Management Review, 33(4), 994-1006.

Lane, P. J., Koka, B. R., \& Pathak, S. (2006). The reification of absorptive capacity: A critical review and rejuvenation of the construct. Academy of Management Review, 31(4), 833-863.

Lane, P. J., \& Lubatkin, M. (1998). Relative absorptive capacity and interorganizational learning. Strategic Management Journal, 19(5), 461-467.

Lane, P. J., Salk, J. E., \& Lyles, A. (2001). IJV learning and performance. Strategic Management Journal, 22(12), 1139-1161.

Langley, A. (1999). Strategies for theorizing from process data. Academy of Management Review, 24(4), $691-710$.

Langley, A., Smallman, C., Tsoukas, H., \& Van De Ven, A. (2013). Process studies of change in organization and management: Unveiling temporality, activity and flow. Academy of Management Journal, 56(1), 1-13. 
Lavie, D. (2006). Capability reconfiguration: An analysis of incumbent responses to technological change. Academy of Management Review, 31(1), 153-174.

Lee, T. W. (1999). Using qualitative methods in organizational research. Thousand Oaks: Sage Publications.

Levinthal, D. A., \& March, J. G. (1993). The myopia of learning. Strategic Management Journal, 14(S2), 95-112.

Levitt, B., \& March, J. G. (1988). Organizational learning. Annual Review of Sociology, 14, 314-340.

Lincoln, Y. S., \& Guba, E. C. (1985). Naturalistic inquiry. Beverly Hills: Sage Publications.

Locke, K. (2001). Grounded theory in management research. Thousand Oaks: Sage Publications.

London, T., \& Hart, S. (2003). Reinventing strategies for emerging markets: Beyond the transnational model. University of North Carolina: Chapel Hill, Working Paper.

Lorange, P., \& Vancil, R. F. (1976). How to design a strategic planning system. Harvard Business Review, 54(5), 75-81.

Lu, J. W., \& Beamish, P. W. (2001). The internationalization and performance of SMEs. Strategic Management Journal, 22(6-7), 565-586.

Menon, A., \& Veradarajan, P. R. (1992). A model of marketing knowledge use within firms. Journal of Marketing, 56(4), 53-71.

Miles, M. B., \& Huberman, A. M. (1994). Qualitative data analysis: An expanded sourcebook. Thousand Oaks: Sage Publications.

Mohr, L. B. (1982). Explaining organizational behavior. San Francisco: Jossey-Bass.

Nag, R., \& Gioia, D. A. (2012). From common to uncommon knowledge: Foundations of firm-specific use of knowledge as a resource. Academy of Management Journal, 55(2), 421-457.

Nelson, R. R., \& Winter, S. G. (1982). An evolutionary theory of economic change. Cambridge: Harvard University Press.

Patton, M. Q. (2002). Qualitative Research and Evaluation Methods. Thousand Oaks: Sage Publications.

Pettigrew, A. M. (1990). Longitudinal field research on change: Theory and practice. Organization Science, 1(3), 267-292.

Prashantham, S., \& Floyd, S. W. (2012). Routine microprocesses and capability learning in international new ventures. Journal of International Business Studies, 43(6), 544-562.

Rondinelli, D. A., \& London, T. (2003). How corporations and environmental groups cooperate: Assessing cross-sector alliances and collaborations. Academy of Management Executive, 17(1), 61-76.

Roth, K., \& Morrison, A. (1992). Implementing global strategy: Characteristics of global subsidiary mandates. Journal of International Business Studies, 23(4), 715-736.

Schilke, O. (2014). On the contingent value of dynamic capabilities for competitive advantage: The nonlinear moderating effect of environmental dynamism. Strategic Management Journal, 35(2), 179-203.

Schleimer, S. C., \& Pedersen, T. (2013). The driving forces of subsidiary absorptive capacity. Journal of Management Studies, 50(4), 646-672.

Simanis, E., \& Hart, S. (2006). Expanding the possibilities at the base of the pyramid. Innovations, 1, 43-49.

Song, J. (2014). Subsidiary absorptive capacity and knowledge transfer within multinational corporations. Journal of International Business Studies, 45(1), 73-84.

Strauss, A., \& Corbin, J. (1998). Basics of qualitative research: Techniques and procedures for developing grounded theory (2nd ed.). Thousand Oaks: Sage Publications.

Suddaby, R. (2006). From the editors: What grounded theory is not. Academy of Management Journal, 49(4), $633-642$.

Teece, D. J. (2014). A dynamic capabilities-based entrepreneurial theory of the multinational enterprise. Journal of International Business Studies, 45(1), 8-37.

Todorova, G., \& Durisin, B. (2007). Absorptive capacity: Valuing a reconceptualization. Academy of Management Review, 32(3), 774-786.

Tripsas, M. (2009). Technology, identity, and inertia through the lens of "The Digital Photography Company". Organization Science, 20(2), 441-460.

Tripsas, M., \& Gavetti, G. (2000). Capabilities, cognition, and inertia: Evidence from digital imaging. Strategic Management Journal, 21(10-11), 1147-1161.

Tsang, E. W. K. (2008). Transferring knowledge to acquisition joint ventures: An organizational unlearning perspective. Management Learning, 39(1), 5-20.

Tsang, E. W. K., \& Zahra, S. (2008). Organizational unlearning. Human Relations, 61(10), 1435-1462.

Uhlenbruck, K., Meyer, K. E., \& Hitt, M. A. (2003). Organizational transformation in transition economies: Resource-based and organizational learning perspectives. Journal of Management Studies, 40(2), 257-283. 
Venaik, S., Midgley, D. F., \& Devinney, T. M. (2005). Dual paths to performance: The impact of global pressure on MNC subsidiary conduct and performance. Journal of International Business Studies, 36(6), $655-675$.

Volberda, H. W., \& Lewin, A. Y. (2003). Co-evolutionary dynamics within and between firms: From evolution to coevolution. Journal of Management Studies, 40(8), 2111-2136.

Webb, J. W., Kistruck, G., Ireland, R. D., \& Ketchen, D. J. (2010). The entrepreneurship process in base of the pyramid markets: The case of multinational/non-government organization alliances. Entrepreneurship Theory and Practice, 34(3), 555-581.

Yang, Q., Mudambi, R., \& Meyer, K. E. (2008). Conventional and reverse knowledge flows in multinational corporations. Journal of Management, 34(5), 882-902.

Yin, R. K. (1984). Case study research. Beverly Hills: Sage Publications.

Zahra, S. A., Abdelgawad, S. G., \& Tsang, E. (2011). Emerging multinationals venturing into developed economies: Implications for learning and entrepreneurial capability. Journal of Management Inquiry, 20(3), 323-330.

Zahra, S. A., \& George, G. (2002). Absorptive capacity: A review, reconceptualization, and extension. Academy of Management Review, 27(2), 185-203.

Zeng, Y. P., Shenkar, O., Lee, S.-H., \& Song, S. (2013). Cultural differences, MNE learning abilities, and the effect of experience on subsidiary mortality in a dissimilar culture: Evidence from Korean MNEs. Journal of International Business Studies, 44(1), 42-65.

Zhang, Y., Li, H. Y., Li, Y., \& Zhou, Li-An. (2010). FDI spillovers in an emerging market: The role of foreign firm's country origin diversity and domestic firm's absorptive capacity. Strategic Management Journal, 31(9), 969-989.

Publisher's Note Springer Nature remains neutral with regard to jurisdictional claims in published maps and institutional affiliations. 